\title{
Clinical significance of lymphocyte subset changes in hemophagocytic lymphohistiocytosis of children
}

\author{
QI AN ${ }^{1,2}$, YI WANG ${ }^{1}$, SHAOYAN HU $^{1}$, DAIHUA FANG ${ }^{2}$, CHENGMIN XUAN $^{2}$, \\ SHUMEI XU ${ }^{2}$, MINGWEI JIN ${ }^{2}$ and QIANG JI ${ }^{2}$ \\ ${ }^{1}$ Department of Hematology and Oncology, Children's Hospital of Soochow University, Suzhou, Jiangsu 215003; \\ ${ }^{2}$ Department of Hematology, Xuzhou Children's Hospital, Xuzhou, Jiangsu 221006, P.R. China
}

Received May 20, 2016; Accepted September 27, 2016

DOI: $10.3892 / \mathrm{etm} .2016 .3809$

\begin{abstract}
In order to examine the role of peripheral blood lymphocyte subsets on the diagnosis, treatment and prognosis of hemophagocytic lymphohistiocytosis (HLH), 30 affected children during the acute period of the disease and 30 healthy children within the same age range were selected to test their peripheral blood lymphocyte subsets using flow cytometry and compare these subsets. At the same time, the peripheral blood lymphocyte subsets of 20 children with complete remission from HLH were compared to those of 10 cases who succumbed to the disease. The proportion of $\mathrm{CD}^{+}$and $\mathrm{CD} 8^{+} \mathrm{T}$ cells were increased in children during the acute period. Additionally, the proportion of $\mathrm{CD} 4^{+} \mathrm{T}$ and $\mathrm{CD} 3{ }^{-} \mathrm{CD} 16^{+} \mathrm{CD} 56^{+}$natural killer (NK) cells and the ratio of $\mathrm{CD}^{+} / \mathrm{CD}^{+}$cells were decreased in the same group of children, with the differences being statistical significance $(\mathrm{P}<0.05)$. The proportion of $\mathrm{CD} 19^{+} \mathrm{B}$ cells showed no differences in the affected and healthy groups. HLH children during the remission period had a higher proportion of $\mathrm{CD}^{+}$and $\mathrm{CD} 8^{+} \mathrm{T}$ cells than that in the control group, but the ratio of $\mathrm{CD} 4^{+} \mathrm{T}$ and $\mathrm{CD} 4^{+} / \mathrm{CD} 8^{+}$ were lower than that in the control group, with the differences being statistically significant $(\mathrm{P}<0.05)$. The proportion of $\mathrm{CD} 19^{+} \mathrm{B}$ cells and $\mathrm{CD} 3{ }^{-} \mathrm{CD} 16^{+} \mathrm{CD} 56^{+} \mathrm{NK}$ cells revealed no significant difference between the two groups. In addition, regarding the proportion of $\mathrm{CD}^{+}, \mathrm{CD}^{+}, \mathrm{CD} 8^{+} \mathrm{T}, \mathrm{CD} 19^{+} \mathrm{B}$ cells, $\mathrm{CD} 3{ }^{-} \mathrm{CD}^{+} 6^{+} \mathrm{CD} 6^{+} \mathrm{NK}$ cells and the ratio of $\mathrm{CD} 4^{+} / \mathrm{CD}^{+}$, and there were no significant differences. The results showed that HLH modifies the peripheral blood lymphocyte subsets and causes cellular immunity disorders. Thus, monitoring these dynamic changes can be useful in the diagnosis of HLH and evaluate the response to therapy.
\end{abstract}

Correspondence to: Dr Yi Wang, Department of Hematology and Oncology, Children's Hospital of Soochow University, 92 Zhongnan Street, Suzhou Industrial Park, Suzhou, Jiangsu 215003, P.R. China E-mail: an_qi1212@163.com

Key words: hemophagocytic lymphohistiocytosis, children, lymphocyte subsets

\section{Introduction}

Hemophagocytic lymphohistiocytosis (HLH), also known as hemophagocytic syndrome (HPS), is a syndrome caused by multiple organ inflammation induced by excessive hyperplasia and activation of lymphocytes and histiocytes, leading to the development of a cytokine storm that resembles a septic syndrome. Clinical manifestations include fever, hepatosplenomegaly, peripheral blood cytopenia, abnormal liver function and blood clotting disorders (1). Although the pathogenesis has not been fully understood, it is considered that a dysregulated immune system plays a major role in HLH (2).

The present study included 30 cases of children diagnosed with non-tumor-associated HLH, at the Children's Hospital of Soochow University, from January, 2009 to March, 2014. The children were treated according to the standards in the HLH-2004 therapeutic regimen. There were 20 cases of complete remission (CR), and 10 mortal cases. Flow cytometry was used to test the peripheral blood lymphocyte subsets in acute and remission phases, and the peripheral blood of healthy children was regarded as the normal control to investigate the clinical significance of the different lymphocyte subsets in pediatric HLH diagnosis, treatment and prognosis.

\section{Patients and methods}

Patients. Children presenting at the Department of Hematology, Xuzhou Children's Hospital, with acute phase HLH in preliminary diagnoses were selected as study subjects. Inclusion criteria for the study were: i) Age, 4 months-10 years; ii) meeting the HLH-2004 criteria of the Histiocyte Association (3); iii) prior to diagnosis, the patient had not used hormones, chemotherapeutic drugs or immune modulators; and iv) the HLH-2004 treatment regimen had not commenced. Children with tumor-associated HLH and congenital immune deficiency were excluded. Thirty healthy children undergoing physical check-ups during the same period at the Xuzhou Children's Hospital were selected for the normal control group. These children had no history of acute or chronic diseases, allergic diseases or familial inherited diseases.

The HLH-2004 standard revision from the Histiocyte Association sets the diagnosis criteria as patients presenting at least five of the following signs (3): i) Fever for $>7$ days, or 
Table I. Results of a comparison of lymphocyte subpopulations in HLH children vs. healthy children (mean \pm SD, \%).

\begin{tabular}{lccccccr}
\hline Groups & $\mathrm{n}$ & $\mathrm{CD} 3^{+}$ & $\mathrm{CD} 4^{+}$ & $\mathrm{CD}^{+}$ & $\mathrm{CD}^{+} / \mathrm{CD}^{+}$ & $\mathrm{CD}^{+} 9^{+}$ & $\mathrm{CD}^{+} 6^{+} \mathrm{CD} 56^{+}$ \\
\hline Acute phase & 30 & $4.48 \pm 14.70$ & $31.43 \pm 15.61$ & $40.06 \pm 22.63$ & $1.32 \pm 0.98$ & $15.8 \pm 10.87$ & $4.74 \pm 3.41$ \\
Remission & 20 & $71.44 \pm 15.02$ & $32.88 \pm 13.88$ & $35.08 \pm 19.22$ & $1.38 \pm 0.96$ & $16.9 \pm 10.34$ & $4.37 \pm 2.84$ \\
Normal control & 30 & $67.37 \pm 4.33$ & $40.05 \pm 6.00$ & $26.64 \pm 3.95$ & $1.74 \pm 0.54$ & $18.45 \pm 3.54$ & $12.31 \pm 3.02$ \\
T-value & & $-2.59^{\mathrm{a}}$ & $2.90^{\mathrm{a}}$ & $-3.94^{\mathrm{a}}$ & $2.20^{\mathrm{a}}$ & $1.28^{\mathrm{a}}$ & $10.37^{\mathrm{a}}$ \\
& $1.19^{\mathrm{b}}$ & $-2.23^{\mathrm{b}}$ & $2.64^{\mathrm{b}}$ & $-1.61^{\mathrm{b}}$ & $-0.64^{\mathrm{b}}$ & $-10.38^{\mathrm{b}}$ \\
P-value & $0.015^{\mathrm{a}}$ & $0.007^{\mathrm{a}}$ & $0.000^{\mathrm{a}}$ & $0.034^{\mathrm{a}}$ & $0.210^{\mathrm{a}}$ & $0.000^{\mathrm{a}}$ \\
& & $0.000^{\mathrm{b}}$ & $0.001^{\mathrm{b}}$ & $0.000^{\mathrm{b}}$ & $0.008^{\mathrm{b}}$ & $0.145^{\mathrm{b}}$ & $0.643^{\mathrm{b}}$
\end{tabular}

${ }^{\mathrm{a} C}$ Comparison is between the acute and normal control groups, ${ }^{\mathrm{b}}$ comparison between the remission and normal control groups. HLH, hemophagocytic lymphohistiocytosis.

a thermal spike of $>38.5^{\circ} \mathrm{C}$; ii) splenomegaly; iii) hypocytosis (accumulation for $>2$ series of peripheral blood cells), hemoglobin $(\mathrm{Hb})<90 \mathrm{~g} / \mathrm{l}$, platelets $<100 \times 10^{9} / 1$, absolute neutrophil count (ANC) $<1.0 \times 10^{9} / 1$; iv) triglycerides (fasting) $\geq 3.0 \mathrm{mmol} / \mathrm{l}$, fibrinogen $\leq 1.5 \mathrm{~g} / \mathrm{l}$; v) hematophages found in bone marrow, spleen or lymph nodes, but without malignant disease basis; vi) diminished natural killer (NK) cell viability or no viability; vii) serum ferritin $\geq 500 \mu \mathrm{g} / \mathrm{l}$; and viii) soluble CD25 [interleukin (IL)-2 receptor] $\geq 2.4 \times 10^{6} / 1$.

The HLH-2004 chemotherapy regimen was used for treatment (3). CR (4) referred to the disappearance of clinical symptoms and signs with normal laboratory tests, including the disappearance of hematophagocytosis in the bone marrow. Following treatment, HLH children with 40 weeks of continuous CR 40 were assigned to the remission group, while any HLH children who succumbed to the disease were considered the death group.

The present study was approved by the Medical Ethics Committee of Xuzhou Children's Hospital. All of the children and their parents agreed to participate and provided written informed consent form.

Specimen collection. Blood samples were drawn from HLH children during teh acute phase and at CR 40 weeks, and from healthy children in the normal control group. Venous blood $(1.5 \mathrm{ml})$ was collected in the morning, mixed with anticoagulant and separated by a centrifugation step.

Lymphocyte subsets determination. For flow cytometry, the cells were mixed with $20 \mu \mathrm{l}$ fluorescent monoclonal antibodies, and incubated for $15 \mathrm{~min}$ at $25^{\circ} \mathrm{C}$, in the dark. The cells were washed with FACS buffer. If required, the cells were permeabilized with FACS solution, prior to incubating with fluorescent antibodies. Isotype controls were used for each staining procedure as negative controls and for compensation of fluorescence. Lymphocyte subpopulations were analyzed using flow cytometric software (De Novo Software, Toronto, ON, Canada). T-lymphocyte surface markers were selected such as $\mathrm{CD}^{+}, \mathrm{CD}^{+}$and $\mathrm{CD}^{+} \mathrm{T}, \mathrm{B}$ lymphocyte markers were $\mathrm{CD} 19^{+}$, and $\mathrm{NK}$ cell markers were $\mathrm{CD}^{+}{ }^{+} \mathrm{CD}^{2} 6^{+}$. Rabbit monoclonal CD3 antibody (dilution, 1/1,000; cat. no. 4443); mouse monoclonal CD4 antibody (dilution, 1/1,000; cat. no. 3563); mouse monoclonal CD8 antibody (dilution, 1/1,000; cat. no. 3572) were purchased from Cell Signaling Technology,
Inc. (Danvers, MA, USA). Rabbit polyclonal CD16 antibody (dilution, 1/1,000; cat. no. ab203883); mouse monoclonal CD19 antibody (dilution, 1/1,000; cat. no. ab31947) and mouse monoclonal CD56 antibody (dilution, 1/1,000; cat. no. ab205500) were purchased from Abcam (Cambridge, MA, USA).

Statistics analysis. The SPSS 13.0 statistical software (Chicago, IL, USA) was used for statistical analysis. Data were shown as mean \pm standard deviation. Whenever the data conformed to the normal distribution with an overall homogeneity of variance, a comparison between two samples and groups was conducted using the t-test. Otherwise, comparisons between groups were carried out using the Wilcoxon rank sum test. $\mathrm{P}<0.05$ was considered to indicate a statistically significant difference.

\section{Results}

General clinical picture of patients. The 30 newly diagnosed HLH children included 17 males and 13 females; with a median age of 1 year (the youngest was 4 months); 12 cases were $<1$ year, and 1 day; 12 more cases were $<3$ years, while the remaining 6 cases were $<10$ years. From the 10 children who succumbed, 6 never achieved CR and succumbed to the disease early within the course of 8 weeks, while the remaining 4 cases had partial remissions but succumbed to the disease before 34 weeks. The 30 healthy children constituted the normal control group (n) and comprised 19 males and 11 females, with a median age of 1 year and 3 months (range, 4 months to 12 years). Gender and age differences between HLH children and the control group were not statistically significant $(\mathrm{P}>0.05)$ making comparisons in the two groups reasonable.

Comparison of lymphocyte subpopulations between HLH children during acute phase and the healthy control children. The cell proportion of $\mathrm{CD}^{+}$and $\mathrm{CD}^{+} \mathrm{T}$ was increased in the HLH children $(\mathrm{P}<0.05)$. By contrast, $\mathrm{CD}^{+} \mathrm{T}$, the specific value of $\mathrm{CD}^{+} / \mathrm{CD}^{+}$and the cell proportion of $\mathrm{CD} 3^{-} \mathrm{CD}^{+} 6^{+} \mathrm{CD} 56^{+} \mathrm{NK}$ decreased $(\mathrm{P}<0.05)$. The differences in $\mathrm{CD} 19^{+} \mathrm{B}$ cell proportion was not statistically significant $(\mathrm{P}>0.05)$ (Table I).

Comparison of lymphocyte subpopulations between remission and dead HLH children. The lymphocyte subpopulations were 
Table II. Results of teh comparison of lymphocyte subpopulations during the preliminary diagnosis between 20 cases of HLH children who survived and those who did not (mean \pm SD, \%).

\begin{tabular}{lccccccc}
\hline Groups & $\mathrm{n}$ & $\mathrm{CD}^{+}$ & $\mathrm{CD}^{+}$ & $\mathrm{CD}^{+}$ & $\mathrm{CD}^{+} / \mathrm{CD}^{+}$ & $\mathrm{CD}^{+}$ & $\mathrm{CD}^{+}$ \\
\hline Remission & 20 & $71.44 \pm 15.02$ & $32.88 \pm 13.88$ & $35.08 \pm 19.22$ & $1.38 \pm 0.96$ & $16.20 \pm 10.90$ & $4.37 \pm 2.84$ \\
Death & 10 & $80.57 \pm 12.57$ & $28.53 \pm 19.09$ & $50.02 \pm 26.57$ & $1.19 \pm 1.06$ & $15.10 \pm 11.36$ & $5.39 \pm 4.44$ \\
T-value & & -1.76 & 0.64 & -1.58 & 0.47 & 0.26 & -0.66 \\
P-value & & 0.382 & 0.254 & 0.198 & 0.485 & 0.924 \\
\hline
\end{tabular}

HLH, hemophagocytic lymphohistiocytosis.

not significantly different in the HLH-affected groups, even after the pairwise comparisons of $\mathrm{CD}^{+}$and $\mathrm{CD}^{+} \mathrm{T}, \mathrm{CD} 4^{+} / \mathrm{CD}^{+}$, $\mathrm{CD} 19^{+} \mathrm{B}$ and $\mathrm{CD} 3{ }^{-} \mathrm{CD} 16^{+} \mathrm{CD}^{-} 6^{+} \mathrm{NK}(\mathrm{P}>0.05)$ (Table II).

\section{Discussion}

HLH is an allergic disease of the mononuclear macrophage system. It is characterized by abnormal hyperplasia of macrophages and phagocytosis of hematocytes (1). HLH can be divided into primary and acquired HLH. Primary HLH includes familial HLH, and HLH can be caused by primary immunodeficiency syndrome. Acquired HLH is secondary to infection, rheumatic diseases or tumors. Clinical manifestations in the present study group included fever, enlargement of liver, spleen and lymph nodes, reduction in peripheral hematocyte numbers, abnormal liver function and coagulation disturbances (including disseminated intravascular coagulation). There are no specific treatments for this disease, and the general practice is to give dexamethasone, cyclosporine A (CsA) and etoposide immune chemotherapy until remission occurs; while the familial HLH is treated with a hematopoietic stem cell transplantation (3). At present, limitations of HLH include susceptibility to cytotoxicity due to NK cells and cytotoxic T cells (CTL) mediating a vesicle release disorder. The immune system responds to antigens excessively, leading to a life-threatening cytokine storm and multi system inflammation (2). Children suffering from HLH are diagnosed by expressing an abnormal immune regulation function with excessive proliferation of viable immune cells, which produce a large number of inflammatory cytokines. Clinical symptoms and laboratory changes can be attributed to the biological effects of cytokines (5).

Analysis of lymphocyte subsets is an important indicator of the detection of cell immunity as well as humoral immune status and it reflects the immune function, and its homeostatic level on the whole. It also assists the diagnosis of certain diseases, analysis of pathogenesis, observation of curative effects and evaluation of the prognosis. $\mathrm{CD}^{+} \mathrm{T}$ cells are the body's total $\mathrm{T}$ cells. $\mathrm{CD}^{+}{ }^{+} \mathrm{T}$ cells, also known as T-helper (Th) cells, connect to the cellular and humoral immunity. $\mathrm{CD}^{+} \mathrm{T}$ cells, including CTL and inhibitory $\mathrm{T}$ cells, enhance the cytotoxic effects to target defective cells and secrete inhibitory factors to weaken or suppress the immune response. The $\mathrm{CD}^{+} / \mathrm{CD}^{+}$ratio is used to broadly examine a person's immune function. Results of the present study showed that during the acute phase, the ratio of $\mathrm{CD}^{+}$and $\mathrm{CD}^{+} \mathrm{T}$ cells in
HLH patients was increased, whereas the ratio of $\mathrm{CD}^{+} \mathrm{T}$ cells and $\mathrm{CD}^{+} / \mathrm{CD}^{+}$cells was significantly decreased. These changes suggested a severe cellular immune dysfunction, with $\mathrm{CD}^{+} \mathrm{T}$-cell proliferation and low cellular immune function. Our findings helped confirmed the diagnosis of HLH in children, but were also in agreement with those of another study in pediatric $\mathrm{HLH}$ which reported an increase of $\mathrm{CD}^{+} \mathrm{T}$ cells and a decrease of the $\mathrm{CD} 4^{+} / \mathrm{CD}^{+}$ratio in affected individuals (6).

The normal cytotoxic function of the immune system can limit the excessive activation of the immune system and thus reduces the development of severe immune pathologies (7). When NK cells and CTL enter in contact with their target cells, a series of cytotoxic activities commences. The process includes synthesis of cytotoxic granules and maturation, polarization to the immunological synapse, dock on the cell membrane, as well as pre-release edition and cell membrane fusion (7). Substances such as perforin and granzymes are released into the target cells and kill these cells. Abnormalities in any of these steps can lead to the failure of the killing effect. Patients suffering from cytotoxic function defects cannot remove the stimulating antigens, causing a lasting expansion of excessive, uncontrolled and deadly antigen-specific $\mathrm{T}$ cells. At the same time, the immune system damage caused by a lack of perforin inhibits apoptosis and makes it possible for $\mathrm{CD}^{+} \mathrm{T}$ cells to receive activation and proliferation signals constantly. Proliferated and activited $\mathrm{CD}^{+} \mathrm{T}$ cells can produce large amounts of interferon (IFN), and IFN- $\gamma$ stimulates the proliferation and activation of macrophages. Macrophages, in turn, can release large amounts of inflammatory cytokines such as IL-12 and TNF-a, IL-2, IL-6, IL-1, IL-10 and GM-CSF, causing a cytokine storm and resulting in an excessive inflammatory response, multiple organ damages, and development of $\operatorname{HLH}(8,9)$.

$\mathrm{CD} 9^{+}$cells regulate the activation and proliferation of $\mathrm{B}$ cells and participate in the signal transduction of B cells. $\mathrm{CD}^{-} \mathrm{CD}^{-} 6^{+} \mathrm{CD} 56^{+}$cells represent a more mature NK cell and are the main components of the non-specific immune system. In the present study, the $\mathrm{CD} 19^{+}$cell proportion in affected and control groups was not different; however the proportion of $\mathrm{CD}^{-} \mathrm{CD}^{-} 6^{+} \mathrm{CD} 56^{+}$cells was significantly lower in the affected group. Therefore, it is possible that while the humoral immunity of HLH patients was normal, the immune function of non-specific natural killer cells was decreased. The HLH-2004 regimen was updated by adding the hypothesis that during HLH there is a decrease or lack of NK cell activity (3). Our results were consistent with those of the HLH-2004 diagnosis 
standard. In addition, other studies found a decreased activity of NK cells in HLH patients $(10,11)$. However, we were not able to detect the viability of NK cells and considered that the cellular immune disorder, the abnormal activation of $\mathrm{CD} 8^{+} \mathrm{T}$ cells and the decrease of $\mathrm{CD} 3{ }^{-} \mathrm{CD} 16^{+} \mathrm{CD} 56^{+}$cells play an important role in the occurrence of HLH.

In the present study, we analyzed lymphocyte subsets at the time of diagnosis of patients in a remission group and of those who succumbed to the disease, albeit we failed to observe any significant differences in the two groups. It is possible that lymphocyte subset abnormalities are not good markers of disease prognosis. Nevertheless, another study found the percentage of $\mathrm{CD}^{+} / \mathrm{CD}^{+}$was inversely proportional to the risk of death (12). The exact timing of the analysis may be a crucial factor for prognostic purposes; however, this remains to be determined. In a study on Epstein-Barr virus-related HLH, it was found that the decrease of NK cells and the increase of $\mathrm{CD}^{+} \mathrm{T}$ lymphocytes were poor prognostic factors (13).

As certain patients with recurrent disease after 8 weeks of initial treatment were identified, we waited 40 weeks to include asymptomatic patients in the remission group. We compared the lymphocyte subsets of HLH-suffering children in the HLH remission and control groups. We found a recovery of $\mathrm{CD} 3{ }^{-} \mathrm{CD} 16^{+} \mathrm{CD} 56^{+} \mathrm{NK}$ proportion in the remission group, with no significant differences between the two groups. However, $\mathrm{CD}^{+}, \mathrm{CD}^{+}, \mathrm{CD} 8^{+}$and $\mathrm{CD} 4^{+} / \mathrm{CD} 8^{+}$remained unchanged without improvement, highlighting the need for the close follow-up of cases, consistent with findings in a different study (14). Another study showed that IFN levels during the period of remission were slightly increased compared with those of the control group (15), which was in agreement with findings of the present study.

In conclusion, HLH patients in the current study presented a lymphocyte subset imbalance, with poor cellular immune functions during the acute period, extending into the remission stages. Future studies are required to gain a better understanding of the pathogenesis of the disease and develop more effective treatment approaches.

\section{References}

1. Bode SF, Lehmberg K, Maul-Pavicic A, Vraetz T, Janka G, Stadt UZ and Ehl S: Recent advances in the diagnosis and treatment of hemophagocytic lymphohistiocytosis. Arthritis Res Ther 14: 213, 2012.
2. Janka G: Hemophagocytic lymphohistiocytosis: when the immune system runs amok. Klin Padiatr 221: 278-285, 2009.

3. Henter JI, Horne A, Aricó M, Egeler RM, Filipovich AH, Imashuku S, Ladisch S, McClain K, Webb D, Winiarski J, et al: HLH-2004: diagnostic and therapeutic guidelines for hemophagocytic lymphohistiocytosis. Pediatr Blood Cancer 48: 124-131, 2007.

4. Janka GE: Hemophagocytic syndromes. Blood Rev 21: 245-253, 2007.

5. Filipovich AH: Hemophagocytic lymphohistiocytosis (HLH) and related disorders. Hematology Am Soc Hematol Educ Program: 127-131, 2009.

6. Xingchao WG and Xie Q: The significance of peripheral blood lymphocyte subgroup detection on immune function evaluation of patients with hemophagocytic syndrome. China Mod Doct 50: 30-31, 2012 (In Chinese). http://www.cnki.com.cn/Article/ CJFDTotal-ZDYS201228017.htm

7. Lykens JE, Terrell CE, Zoller EE, Risma K and Jordan MB: Perforin is a critical physiologic regulator of T-cell activation. Blood 118: 618-626, 2011.

8. Tang YM and Xu XJ: Advances in hemophagocytic lymphohistiocytosis: pathogenesis, early diagnosis/differential diagnosis, and treatment. ScientificWorldJournal 11: 697-708, 2011.

9. Janka GE: Familial and acquired hemophagocytic lymphohistiocytosis. Eur J Pediatr 166: 95-109, 2007.

10. Chung HJ, Park CJ, Lim JH, Jang S, Chi HS, Im HJ and Seo JJ: Establishment of a reference interval for natural killer cell activity through flow cytometry and its clinical application in the diagnosis of hemophagocytic lymphohistiocytosis. Int J Lab Hematol 32: 239-247, 2010.

11. Wang WL, Chen X, Wang R and Wang J-S: Application on the diagnosis of acquired hemophagocytic lymphohistiocytosis of flow cytometry method tests the NK cell viability. J Exp Hematol 17: 1497-1501, 2009 (In Chinese).

12. Cheng Y, Hao G, Wang X, et al: Hemophagocytic syndrome and analysis on clinical characteristics and death related factors. J Changzhi Med Coll 11: 20-22, 2011 (In Chinese).

13. Kogawa K, Lee SM, Villanueva J, Marmer D, Sumegi J and Filipovich AH: Perforin expression in cytotoxic lymphocytes from patients with hemophagocytic lymphohistiocytosis and their family members. Blood 99: 61-66, 2002.

14. Jin Y, Xie Z, Du Z, et al: Retrospective analysis on epstein-barr virus related hemophagocytic lymphohistiocytosis of children. J Cap Med Univ 31: 192-195, 2010 (In Chinese).

15. Xu XJ, Tang YM, Zhao N, Song H, Yang SL, Shi SW, Xu WQ, Pan BH, Zhang LY, Mao JQ, et al: Diagnostic significance of Th1/Th2 cytokine pattern in childhood hemophagocytic lymphohistiocytosis. Zhonghua Er Ke Za Zhi 49: 685-689, 2011 (In Chinese). 